\title{
Examining the relationship between free recall and immediate serial recall: The serial nature of recall and the effect of test expectancy
}

\author{
Parveen Bhatarah \\ London Metropolitan University, London, England \\ GEOFF WARD \\ University of Essex, Colchester, England \\ AND \\ LYDIA TAN \\ City University London, London, England
}

\begin{abstract}
In two experiments, we examined the relationship between free recall and immediate serial recall (ISR), using a within-subjects (Experiment 1) and a between-subjects (Experiment 2) design. In both experiments, participants read aloud lists of eight words and were precued or postcued to respond using free recall or ISR. The serial position curves were U-shaped for free recall and showed extended primacy effects with little or no recency for ISR, and there was little or no difference between recall for the precued and the postcued conditions. Critically, analyses of the output order showed that although the participants started their recall from different list positions in the two tasks, the degree to which subsequent recall was serial in a forward order was strikingly similar. We argue that recalling in a serial forward order is a general characteristic of memory and that performance on ISR and free recall is underpinned by common memory mechanisms.
\end{abstract}

Free recall and immediate serial recall (ISR) are two immediate memory tasks in which participants are presented with lists of words to study, one word at a time, and then, after the presentation of the last word in a list, they must try to recall as many of the items as they can. In free recall, participants are free to recall the items in any order that they wish, whereas under ISR instructions, participants must try to recall the items in exactly the same order as that in which they were presented. In this article, we examine the similarities and differences between free recall and ISR when the tasks are performed under essentially identical methodological conditions.

One similarity between free recall and ISR is that both tasks have provided influential evidence suggesting the existence of a highly accessible but temporary short-term memory store (STS) of limited capacity. In immediate free recall, the last few words in a list are typically recalled more often than words from earlier in the list, a phenomenon known as the recency effect, and the classic explanation is that the last few words are output directly from the STS (Atkinson \& Shiffrin, 1971; Glanzer, 1972; Waugh \& Norman, 1965). In ISR, the memory span refers to the number of items that can be immediately repeated in the correct order on $50 \%$ of the trials. The classic explanation for the memory span is that it reflects the capacity limitations of the STS, in terms of either the number of chunks of items that can be recalled (e.g., Miller, 1956) or the effective duration of a verbal sequence that can be maintained (e.g., Baddeley, Thomson, \& Buchanan, 1975).

However, a common STS explanation of both recency and ISR (such as that characterized by the modal model: Murdock, 1967) now seems untenable. Baddeley and Hitch $(1974,1977)$ presented participants with lists of 16 words for free recall; throughout the list, they were also presented with several sequences of digits, which they either recalled in the correct serial order (in the experimental, concurrent ISR digit load condition) or copied down as they were presented (control condition). They found that performing ISR on several sequences of three or even six digits throughout a list did not reduce the magnitude of the recency effect in free recall, relative to the control condition. This lack of a trade-off between recency and ISR appears contrary to a common, unitary STS account of memory span and recency.

Bhatarah, Ward, and Tan (2006) recently replicated and extended this finding. In a series of experiments, par- 
ticipants studied lists of 16 words for free recall either while performing a six-digit ISR task throughout the list or in the absence of any digits (control). The timing of the words and the digits was improved, so that the digits were always presented during the intervals between the words and there was always a fresh six-digit sequence to listen to and repeat back after each and every word, including the last. If ISR and free recall were underpinned by the same STS, the six-digit ISR task should displace the words from the STS, thereby reducing or eliminating the recency effect. In line with Baddeley and Hitch's $(1974,1977)$ findings, Bhatarah et al. found that a continuous ISR load did not decrease the magnitude of the recency effect in free recall, a finding contrary to a common STS explanation of recency and ISR. This occurred (1) when the words were presented visually in silence, (2) when the words were read out loud from the screen during presentation, (3) when the participants said out loud those words that they were currently thinking about (overt rehearsal), and (4) when the participants continually rehearsed out loud only the most recently presented word (fixed rehearsal).

The interpretation preferred by Baddeley and Hitch (1974) was to exclude recency effects from the STS. However, they maintained that an STS mechanism, the phonological loop, underpinned ISR. One difficulty with this interpretation (discussed more fully by Ward, 2001) is that it is unclear why an STS mechanism might support only one task, but not the other: it seems reasonable to suppose that any STS mechanism used to manipulate and maintain a short list of words for ISR might also usefully provide temporary storage for words to be recalled in free recall, especially if one were to use identical methodologies to present sequences of words for free recall and ISR. The first aim of this article is to explore this tension directly, by examining free recall and ISR performance under identical methodological conditions.

We should be clear that this tension is readily generalizable to any account of ISR or free recall that proposes that one or the other task is supported by the STS. Put simply, the data of Baddeley and Hitch $(1974,1977)$ that have been replicated and extended by Bhatarah et al. (2006) necessitate that any STS mechanisms involved in ISR cannot also be responsible for recency performance in free recall at test. Thus, when models of ISR are proposed that are assumed to be computational accounts of the STS (e.g., Burgess \& Hitch, 1992, 1999; Henson, 1998; Page \& Norris, 1998), it must be presumed that these same STS mechanisms cannot underpin recency performance in free recall (where, arguably, one might think that they might be useful). Similarly, when models of free recall, such as that proposed by Davelaar, Goshen-Gottstein, Ashkenazi, Haarmann, and Usher (2005), argue for a short-term memory buffer that is used to output recency items in free recall, this same limited-capacity STS mechanism cannot be extended to support ISR performance (where, again, one might think it could be useful).

One response to this tension is the argument that, despite certain superficial similarities, ISR and free recall are fundamentally different tasks. ISR requires memory for items to be in the correct order, whereas free recall does not, and it may be that the serial nature of output in ISR is a distinction that is sufficiently important to justify separate immediate mechanisms for ISR and free recall. However, a number of recent studies have highlighted the forward serial order nature of free recall (e.g., Bhatarah et al., 2006; Howard \& Kahana, 1999, 2002a; Kahana, 1996; Laming, 1999, 2006; Ward, Woodward, Stevens, \& Stinson, 2003), although comparisons between existing free recall and ISR data are made difficult because longer lists are typically used in free recall than in ISR. A second aim of this article is, therefore, to compare the degree of forward-order serial recall in free recall and ISR under equivalent methodological conditions.

A final consideration is that participants might encode the two tasks differently and, thereby, make use of different memory mechanisms. If participants know in advance that they will be tested with ISR, they might strategically use ISR-specific mechanisms, whereas if they know in advance that the test will be free recall, they might make use of freerecall-specific mechanisms. A strategic encoding explanation could ensure that there was no overlap between the memory mechanisms underpinning ISR and free recall and, so, could provide one explanation for the lack of a trade-off between ISR and recency (Baddeley \& Hitch, 1974, 1977; Bhatarah et al., 2006). This idea, too, will be examined in this article by manipulating test expectancy. If participants in some conditions are told of the type of test to be used only at the end of the list (i.e., the instructions are postcued), one may assume that the list was encoded similarly in the two tasks. Furthermore, if postcued performance on free recall and ISR is similar to precued performance (when participants are told in advance which task they are to perform), it is difficult to argue that precued free recall and precued ISR are normally encoded in different ways.

We should note that not all accounts of free recall (e.g., Crowder, 1993) and ISR (e.g., Nairne, 2002) presume the involvement of limited-capacity STS mechanisms. As such, it might be possible that both tasks could be underpinned by the same general (non-STS) memory mechanisms. Certainly, many researchers have argued that recency is a general property of memory (e.g., Bhatarah et al., 2006; Brown, Neath, \& Chater, 2007; Crowder, 1982, 1993; Crowder \& Neath, 1991; Glenberg, 1984, 1987; Glenberg et al., 1980; Howard \& Kahana, 1999, 2002a, 2002b; Kahana, 1996; Laming, 1999, 2006; Lewandowsky, Nimmo, \& Brown, in press; Neath \& Brown, 2006; Neath \& Crowder, 1990; Tan \& Ward, 2000; Ward, 2001; Ward \& Tan, 2004). Many also have argued that output in ISR, free recall, or, indeed, other tasks (such as free reconstruction of order) progresses in a forward serial order (Bhatarah et al., 2006; Howard \& Kahana, 1999, 2002a, 2002b; Kahana, 1996; Laming, 1999, 2006; Lewandowsky, Brown, Wright, \& Nimmo, 2006; Tan \& Ward, in press; Ward et al., 2003).

Nevertheless, it is rare that an attempt is made in a single account of memory to explain both free recall and ISR, without recourse to the STS. One such attempt is the scale-invariant memory, perception, and learning model (SIMPLE; Brown et al., 2007; Neath \& Brown, 2006). In this account, items for ISR and free recall are encoded in 
terms of their position along a temporal-contextual continuum, rather than in a separate STS and long-term memory store. Recall is based on the temporal distinctiveness of the stimuli within the list, and it is assumed that temporal distances become compressed at longer retention intervals. Such an account essentially predicts recency over all timescales, together with a small amount of primacy, if the first few list items are not preceded by other, similar items. The differences in the shapes of the serial position curves in free recall and ISR can be explained if one considers the differences in the output orders in the two tasks. In ISR, words must be output in strict forward order and primacy dominates, whereas in free recall, the end items tend to be recalled first and there is more recency.

However, although recent evidence from Lewandowsky and colleagues has provided some support for the importance of temporal distinctiveness in free recall (e.g., Brown, Morin, \& Lewandowsky, 2006) and free reconstruction of order (Lewandowsky et al., in press), other research has called into question whether temporal distinctiveness is the critical dimension in strict forward order ISR (e.g., Lewandowsky et al., 2006; Lewandowsky, Duncan, \& Brown, 2004; Nimmo \& Lewandowsky, 2005, 2006). Rather, the effects of manipulating the temporal characteristics at input and output in ISR suggest that immediate memory is event based, rather than time based, and suggest that ISR may require the use of positional, rather than temporal, codes. In principle, a process version of SIMPLE (Brown et al., 2007; Neath \& Brown, 2006) could explain the forward-ordered effects of output in free recall (Howard \& Kahana, 1999; Kahana, 1996), but this has not yet been done.

An alternative general memory model, the temporal context model (TCM; Howard \& Kahana, 2002a), provides a basis for recency and an explanation for the forwardordered output effects found in memory tasks. Recency is explained by changes in context throughout the list. Part of the change in context is caused by contextual drift, but the remainder is caused by the addition to the learning context of the preexperimental semantic information of new study items. This second factor helps explain the asymmetric forward temporal and semantic associations between items in a list (Howard \& Kahana, 2002b). To date, the model has been applied to free recall under immediate, delayed, and continuous distractor conditions (Howard \& Kahana, 1999) and accounts for data from serial and free recall learning (Klein, Addis, \& Kahana, 2005), data from probed recall of serial lists (Kahana \& Caplan, 2002), and data from pairedassociate learning (Kahana, 2002; Rizzuto \& Kahana, 2001). In principle, the account could be applied to ISR for short lists of words, although this has not yet been done.

\section{EXPERIMENT 1}

In Experiment 1, we therefore examined free recall and ISR under similar methodological conditions. The aim was to examine the degree to which output would be forward ordered in the two tasks and also examined whether participants would make use of different encoding strategies when they were expecting free recall and ISR tasks.
In Experiment 1, the type of task and the test expectancy was manipulated within subjects. Each participant therefore received (1) a block of trials on which they knew in advance that they would be tested by free recall (the precued free recall condition), (2) a block of trials on which they knew in advance that they would be tested by ISR (the precued ISR condition), and (3) two blocks of trials on which the task to be performed at test was randomly allocated on each trial and was unknown during encoding but was cued immediately prior to recall (each of the blocks contained postcued free recall and postcued ISR conditions in a randomized order). On all the trials, the participants saw a precue instruction, read aloud a sequence of eight visually presented words, and saw a postcue instruction. The precue instruction either informed the participants of the task to be performed at test (the precued conditions) or else was a series of question marks (in the postcued conditions); the postcue instruction always informed the participants of the task to be performed at test.

Of interest was whether the different-shaped serial position curves characteristic of free recall and ISR when different encoding strategies could be used (precued conditions) would also be obtained when such differential strategies could not be used (postcued conditions). In addition, the output orders were examined to determine the extent of forward-ordered recall in the four conditions.

\section{Method}

Participants. Twenty-four students from the University of Essex participated in this experiment in exchange for $£ 5$.

Materials and Apparatus. The materials for each participant consisted of 288 words randomly selected from a set of 478 words taken from the Toronto Word Pool (Friendly, Franklin, Hoffman, \& Rubin, 1982). The materials were presented using the Supercard application on an Apple Macintosh G4 computer with a 16-in. computer monitor. A tape recorder was used to record the participants' recall responses.

Design. The experiment used a within-subjects design. For each task (free recall and immediate serial recall), there were two withinsubjects independent variables: test expectancy with two levels (precued or postcued), and serial position of the list items with eight levels (SPs 1, 2, 3, 4, 5, 6, 7, or 8).

Procedure. The participants were tested individually and were informed that they would be shown four practice lists of eight words, followed by 32 experimental lists of eight words. The experimental trials were arranged into four blocks of eight trials. In one block, the participants were always told in advance that the task would be free recall; in a different block, the participants were always told in advance that the task would be ISR; and in two other blocks, the participants did not know in advance the task to be performed. Each participant was randomly allocated to one of the 24 different orderings of the four blocks of trials. The participants were told to recall as many words as they could in any order that they wished for the free recall trials and to recall as many words as they could in the same order (saying "blank" when an item was forgotten, in order to maintain serial order) on the ISR trials. The participants were instructed to vocalize their recalled items during the recall period, and a tape recorder was used to record the participants' responses. Each trial started with a warning tone, followed after $3 \mathrm{sec}$ by the precue instruction, which appeared for $3 \mathrm{sec}$ in the same position on the screen as the stimuli. The precue instruction was "any order" or "same order" (in the precued free recall and precued ISR conditions, respectively) or was "?????????" (in the postcued conditions). After an additional $2 \mathrm{sec}$ in which the stimulus field was blank, there was a second warning tone, an additional $1-\mathrm{sec}$ pause, followed by the 
eight words presented one at a time in the stimulus field in the center of the screen. The presentation rate was one word every $3 \mathrm{sec}$, with each word displayed for $1 \mathrm{sec}$ with an additional 2-sec interstimulus interval in which the stimulus field was blank. The participants read each word aloud as it was presented. After the last item, a postcue instruction was displayed for $2 \mathrm{sec}$ that read either "any order" or "same order" (in the free recall and ISR conditions, respectively). The participants then heard three beeps signaling the start of the 25 -sec recall period, and they recalled their responses out loud, their responses being recorded by a tape recorder.

\section{Results}

All the data were included in the following analyses. The results for free recall and ISR were first analyzed separately, and then the output orders across tasks and conditions were analyzed.

Free recall. The proportions of words recalled at each serial position for the free recall tasks are shown in Figure $1 \mathrm{~A}$. A $2 \times 8$ within-subjects ANOVA with two factors, test expectancy (postcued or precued) and serial position (SPs 1, 2, 3, 4, 5, 6, 7, or 8), revealed a nonsignificant main effect of test expectancy $\left[F(1,23)=0.35, M S_{\mathrm{e}}=0.030, p>\right.$ $.05]$, a significant main effect of serial position $[F(7,161)=$ $\left.17.35, M S_{\mathrm{e}}=0.054, p<.01\right]$, and a nonsignificant interaction $\left[F(7,161)=1.80, M S_{\mathrm{e}}=0.028, p>.05\right]$.

Tukey HSD pairwise comparisons on the significant main effect of serial position revealed significant differences between SP 1 and SP 4 (showing significant primacy), and between SP 4 and SP 6, and for all pairwise comparisons between SPs 7-8 and SPs 1-6 (showing significant recency).

ISR. The proportions of words recalled in correct serial order for each serial position in the ISR tasks are displayed in Figure 2A. A $2 \times 8$ within-subjects ANOVA with two factors, test expectancy (precued or postcued) and serial position (SPs 1, 2, 3, 4, 5, 6, 7, or 8), revealed a nonsignificant main effect of test expectancy $[F(1,23)=$ 2.38, $\left.M S_{\mathrm{e}}=0.039, p>.05\right]$, a significant main effect of serial position $\left[F(7,161)=26.74, M S_{\mathrm{e}}=0.047, p<\right.$ $.01]$, and a nonsignificant interaction $[F,(7,161)=1.15$, $\left.M S_{\mathrm{e}}=0.024, p>.05\right]$. Tukey HSD pairwise comparisons on the significant main effect of serial position revealed significant differences between all pairwise comparisons between SPs 1-2 and SPs 3-8 and for each comparison between SP 3 and SP 6-7 (showing significant primacy) and no significant recency advantage.

Output order. Table 1 shows the number of list items recalled in the different output positions. In the table, "blank" refers to either an intrusion or the participant's saying "blank"; "no response" refers to the point at which the participant, having finished recall on a given trial, does not produce any further responses. When ISR was precued, the first word outputted was SP 1 on 141 of 192 possible responses, $(M=.73)$, and when ISR was postcued, the first output was SP 1 on 136 of 192 possible responses, $(M=.71)$. In line with ISR instructions, the frequencies of words output at different serial positions are clustered around the leading diagonal, indicating that the participants outputted words more or less accurately according to their serial position.

In the free recall data sets, there was also some indication of recall starting from SP 1, although this proportion
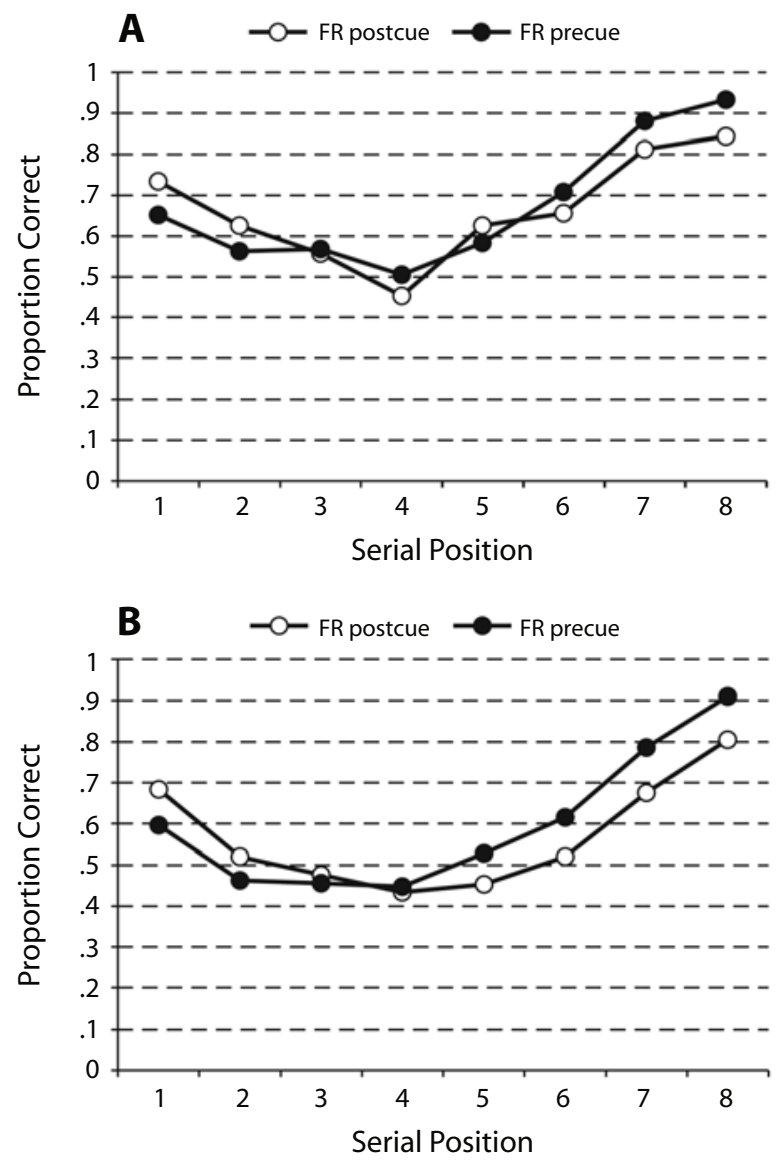

Figure 1. Free recall data. (A) Mean proportion of correct responses for the words in the free recall (FR) conditions in Experiment 1 , when the participants knew the method of testing in advance of the list (precued FR) and when they knew the method of testing only after encoding the list but immediately prior to recall (postcued FR). (B) Precued FR and postcued FR data from Experiment 2.

was considerably lower than that for ISR (41 out of 192 possible responses $[M=.21]$ and 59 out of 192 possible responses $[M=.31]$ for precued free recall and postcued free recall, respectively). However, in free recall, the participants tended more often to output later list items first. The proportions of trials on which recall was initiated with an item from the second half of the list (SPs 5-8) were 137 out of 192 possible responses $(M=.71)$ for the precued free recall condition and 119 of 192 possible responses ( $M=.62)$ for the postcued free recall condition, values considerably greater than those for the ISR data.

Table 2 shows the transitions between consecutive words recalled. From these transitions, one can calculate the lag (Howard \& Kahana, 1999, 2002b; Kahana, 1996) by subtracting the serial position of the word recalled in output position $n$ from the word recalled in output position $n+1$. Of particular interest are the numbers of lag +1 responses across the free recall and ISR conditions. Lag +1 corresponds to responses that are output in forward serial order, such as a word from SP 2 following a word from SP 1, a word from SP 3 following a word from SP 2, and so forth. 

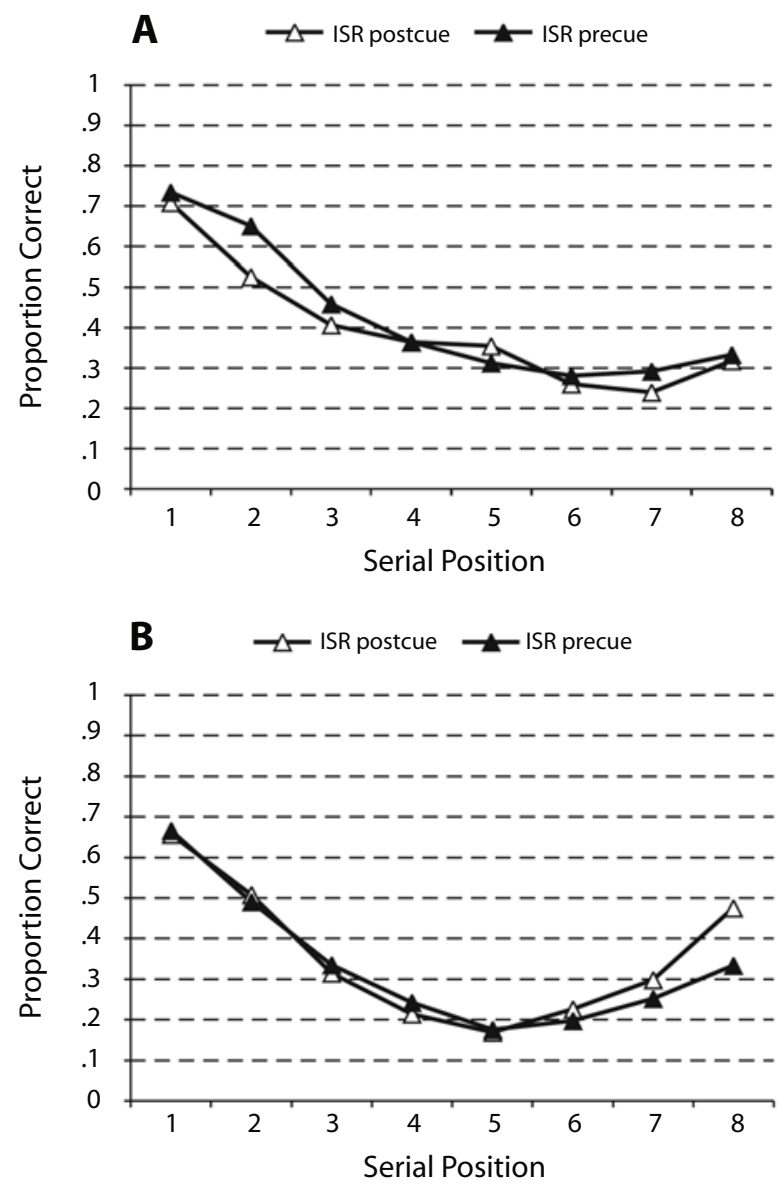

Figure 2. Immediate serial recall (ISR) data. (A) Mean proportion of correct responses for the words in the correct serial position in the ISR conditions in Experiment 1, when the participants knew the method of testing in advance of the list (precued ISR) and when they knew the method of testing only after encoding the list but immediately prior to recall (postcued ISR). (B) Precued ISR and postcued ISR data from Experiment 2.

Lag +1 responses are the most frequent in all four conditions, totaling 311 and 320 responses for the free recall precued and postcued conditions, respectively, and 411 and 377 responses for the ISR precued and postcued conditions, respectively. One can also see that the number of negative lags (the values above the leading diagonal in each subtable) is far greater in the free recall conditions (373 and 331 for free recall precued and free recall postcued conditions, respectively) than in the ISR conditions ( 39 and 32 for ISR precued and ISR postcued conditions, respectively). There are also far more "blank" responses in the ISR conditions (372 and 435, precued ISR and postcued ISR, respectively) than in the free recall conditions (13 and 36, precued free recall and postcued free recall, respectively).

Before interpreting these lag data, one needs to take into account not only the number of transitions made at different lags, but also the opportunity to make transitions at different lags. The opportunity to make transitions at different lags is affected by a range of factors. First, different numbers of responses were made in the different experimental conditions: If one condition leads to fewer responses than does another, there will be less opportunity to make transitions of particular lag values in that first condition, and the frequency of occurrence of lags of +1 will tend to be reduced. Second, only a limited range of lags is possible following the recall of a given word, so that the opportunity to make lags of particular values is determined by what has been output earlier in the sequence. One consequence is that there is generally greater opportunity to make transitions of lag +1 and -1 than lags of greater absolute value. Lags of +7 , for example, can arise only from a single combination of words recalled (when a word from SP 1 is output immediately before a word from SP 8), whereas a lag of +1 can arise following seven different combinations of outputs (a word from SP 1 followed by a word from SP 2, a word from SP 2 followed by a word from SP 3, etc.). A second consequence is that if recall starts from the very beginning of the list (as is more typically the case in ISR), there will be no opportunity to provide a lag of negative values on the subsequent item. By contrast, if recall starts from the very end of the list (as is more often the case in free recall), there will be no opportunity to provide a lag of positive values on the subsequent item. Finally, one needs to take into account the fact that participants are unlikely to output the same item twice on any given trial.

To take into account all of these factors, we can calculate the probability of recall at different lags by dividing the frequency with which each lag was made by the frequency with which each lag could reasonably have been made at each point throughout the list. This analysis was pioneered by Kahana and colleagues (e.g., Howard \& Kahana, 1999; Kahana, 1996), who plotted lag as a function of the conditionalized response proportions, which were calculated for each participant and each lag in the manner outlined above. One complication is that our data must also accommodate responses in which the participants said "blank." We assume that it is impossible to calculate a lag transition when recall progresses to, or from, a "blank." However, when "blank" is made as a response, it is sometimes possible to assign lag values of words that could have been alternatively output. Therefore, although the frequency of actual lag transitions does not increase with a "blank" response, the frequency of opportunities to make transitions of particular lag values can increase. The Appendix provides a worked example to help readers understand how these values were calculated.

Figure $3 \mathrm{~A}$ shows the probability that words from different lags were recalled for each of the four conditions. All recall lag functions show that the most frequent transition between responses was that of lag +1 . Critically, a 2 (task: free recall or ISR) $\times 2$ (test expectancy: precued or postcued) ANOVA showed that there was no significant main effect of task $\left[F(1,23)=0.959, M S_{\mathrm{e}}=0.020, p>\right.$ $.05]$, no significant main effect of expectancy $[F(1,23)=$ $\left.0.389, M S_{\mathrm{e}}=0.012, p>.05\right]$, and no significant interaction $\left[F(1,23)=0.72, M S_{\mathrm{e}}=0.007, p>.05\right]$. This indicates that when one controls for the opportunity to make responses of different lag transitions, the proportion of forward serial ordered responses was similar across the four conditions. 
Table 1

Data From Experiment 1

\begin{tabular}{|c|c|c|c|c|c|c|c|c|c|}
\hline \multirow[b]{2}{*}{ Serial Position } & \multicolumn{8}{|c|}{ Output Position } & \multirow[b]{2}{*}{ Tota } \\
\hline & 1 & 2 & 3 & 4 & 5 & 6 & 7 & 8 & \\
\hline \multicolumn{10}{|c|}{ Precued Free Recall } \\
\hline SP 1 & 41 & 8 & 11 & 24 & 20 & 9 & 9 & 3 & 125 \\
\hline SP 2 & 6 & 26 & 12 & 15 & 19 & 22 & 6 & 2 & 108 \\
\hline SP 3 & 2 & 4 & 30 & 17 & 28 & 13 & 12 & 3 & 109 \\
\hline SP 4 & 3 & 8 & 15 & 28 & 18 & 14 & 3 & 8 & 97 \\
\hline SP 5 & 26 & 15 & 24 & 16 & 15 & 12 & 3 & 1 & 112 \\
\hline SP 6 & 16 & 36 & 31 & 28 & 10 & 9 & 3 & 3 & 136 \\
\hline SP 7 & 24 & 62 & 39 & 16 & 11 & 8 & 9 & 0 & 169 \\
\hline SP 8 & 71 & 33 & 24 & 29 & 8 & 7 & 5 & 2 & 179 \\
\hline "Blank" & 3 & 0 & 4 & 1 & 2 & 1 & 2 & 0 & 13 \\
\hline No response & 0 & 0 & 2 & 18 & 61 & 97 & 140 & 170 & 488 \\
\hline Total & 192 & 192 & $19 \overline{2}$ & 192 & 192 & 192 & 192 & 192 & 1,536 \\
\hline \multicolumn{10}{|c|}{ Postcued Free Recall } \\
\hline SP 1 & 59 & 7 & 18 & 24 & 20 & 4 & 5 & 4 & 141 \\
\hline SP 2 & 1 & 48 & 8 & 14 & 20 & 18 & 8 & 3 & 120 \\
\hline SP 3 & 5 & 8 & 42 & 17 & 10 & 14 & 10 & 1 & 107 \\
\hline SP 4 & 6 & 6 & 13 & 28 & 9 & 17 & 4 & 4 & 87 \\
\hline SP 5 & 21 & 11 & 25 & 23 & 27 & 7 & 4 & 2 & 120 \\
\hline SP 6 & 9 & 30 & 30 & 18 & 13 & 20 & 4 & 2 & 126 \\
\hline SP 7 & 22 & 54 & 31 & 15 & 15 & 6 & 10 & 3 & 156 \\
\hline SP 8 & 67 & 25 & 13 & 25 & 12 & 10 & 4 & 6 & 162 \\
\hline "Blank" & 2 & 3 & 9 & 7 & 7 & 4 & 4 & 0 & 36 \\
\hline No response & 0 & 0 & 3 & 21 & 59 & 92 & 139 & 167 & 481 \\
\hline Total & 192 & 192 & 192 & 192 & 192 & 192 & 192 & 192 & 1,536 \\
\hline \multicolumn{10}{|c|}{ Precued ISR } \\
\hline SP 1 & 141 & 3 & 2 & 0 & 0 & 0 & 0 & 0 & 146 \\
\hline SP 2 & 5 & 125 & 4 & 2 & 0 & 0 & 0 & 0 & 136 \\
\hline SP 3 & 3 & 7 & 88 & 11 & 0 & 1 & 0 & 0 & 110 \\
\hline SP 4 & 1 & 3 & 23 & 70 & 4 & 0 & 1 & 0 & 102 \\
\hline SP 5 & 0 & 1 & 8 & 16 & 60 & 7 & 4 & 0 & 96 \\
\hline SP 6 & 0 & 2 & 0 & 9 & 13 & 54 & 7 & 2 & 87 \\
\hline SP 7 & 0 & 1 & 1 & 4 & 13 & 21 & 56 & 9 & 105 \\
\hline SP 8 & 1 & 0 & 1 & 1 & 7 & 13 & 13 & 64 & 100 \\
\hline "Blank" & 41 & 49 & 58 & 69 & 74 & 52 & 29 & 0 & 372 \\
\hline No response & 0 & 1 & 7 & 10 & 21 & 44 & 82 & 117 & 282 \\
\hline Total & 192 & 192 & 192 & 192 & 192 & 192 & 192 & 192 & 1,536 \\
\hline \multicolumn{10}{|c|}{ Postcued ISR } \\
\hline SP 1 & 136 & 3 & 1 & 1 & 0 & 1 & 0 & 0 & 142 \\
\hline SP 2 & 2 & 101 & 5 & 2 & 1 & 1 & 0 & 0 & 112 \\
\hline SP 3 & 3 & 8 & 78 & 6 & 1 & 0 & 1 & 0 & 97 \\
\hline $\mathrm{SP} 4$ & 0 & 1 & 14 & 70 & 1 & 0 & 1 & 0 & 87 \\
\hline SP 5 & 3 & 1 & 8 & 14 & 68 & 6 & 1 & 0 & 101 \\
\hline SP 6 & 0 & 2 & 2 & 6 & 16 & 50 & 8 & 3 & 87 \\
\hline SP 7 & 0 & 0 & 2 & 5 & 9 & 21 & 46 & 7 & 90 \\
\hline SP 8 & 0 & 0 & 1 & 2 & 7 & 10 & 18 & 61 & 99 \\
\hline "Blank" & 46 & 73 & 74 & 73 & 68 & 61 & 40 & 0 & 435 \\
\hline No response & 2 & 3 & 7 & 13 & 21 & 42 & 77 & 121 & 286 \\
\hline Total & 192 & 192 & 192 & 192 & 192 & 192 & 192 & 192 & 1,536 \\
\hline
\end{tabular}

Note-The four subtables show the distribution of words recalled by serial position (SP) and output position for the four experimental conditions (from top to bottom): precued free recall, postcued free recall, precued immediate serial recall (ISR), and postcued ISR. "Blank" refers to the participant's saying "blank"; "no response" refers to the point at which the participant, having finished recall on a given trial, did not produce any further responses.

\section{Discussion}

There were three main findings. First, there were different serial position curves for free recall (U-shaped) and ISR (extended primacy with no recency) in the precued blocks of trials, which closely resembled the curves in the postcued blocks of trials. The lack of recency in ISR may be due to the verbal recall's acting as a stimulus suffix, and participants often provided fewer than eight responses in their verbal output, perhaps indicating that they had lost track of the number of responses that they had made with an oral method of responding.

Second, analyses of the output order show that the participants almost always started to recall from the beginning of the list in ISR but more often started recalling 
Table 2

Data From Experiment 1

\begin{tabular}{|c|c|c|c|c|c|c|c|c|c|c|c|c|}
\hline \multirow[b]{2}{*}{$\begin{array}{l}\text { Serial Position of } \\
\text { Output Position } n\end{array}$} & \multicolumn{11}{|c|}{ Serial Position of Prior Item (Output Position $n-1$ ) } & \multirow[b]{2}{*}{ Total } \\
\hline & 1 & 2 & 3 & 4 & 5 & 6 & 7 & 8 & - & Blank & $\begin{array}{c}\text { No } \\
\text { Response }\end{array}$ & \\
\hline \multicolumn{13}{|c|}{ Precued Free Recall } \\
\hline SP 1 & 0 & 16 & 13 & 7 & 7 & 8 & 11 & 20 & 41 & 2 & 0 & 125 \\
\hline SP 2 & 53 & 0 & 11 & 9 & 8 & 7 & 6 & 7 & 6 & 1 & 0 & 108 \\
\hline SP 3 & 14 & 33 & 0 & 15 & 3 & 17 & 12 & 11 & 2 & 2 & 0 & 109 \\
\hline SP 4 & 7 & 13 & 33 & 0 & 7 & 6 & 13 & 15 & 3 & 0 & 0 & 97 \\
\hline SP 5 & 10 & 5 & 9 & 16 & 0 & 14 & 11 & 19 & 26 & 2 & 0 & 112 \\
\hline SP 6 & 8 & 4 & 7 & 6 & 48 & 0 & 19 & 26 & 16 & 2 & 0 & 136 \\
\hline SP 7 & 1 & 6 & 5 & 11 & 15 & 51 & 0 & 55 & 24 & 1 & 0 & 169 \\
\hline SP 8 & 4 & 3 & 5 & 4 & 5 & 8 & 77 & 0 & 71 & 2 & 0 & 179 \\
\hline "Blank" & 1 & 1 & 0 & 3 & 0 & 2 & 1 & 2 & 3 & 0 & 0 & 13 \\
\hline No response & 24 & 25 & 23 & 18 & 18 & 20 & 19 & 22 & 0 & 1 & 318 & 488 \\
\hline Total & 122 & 106 & 106 & 89 & 111 & 133 & 169 & 177 & 192 & 13 & 318 & 1,536 \\
\hline \multicolumn{13}{|c|}{ Postcued Free Recall } \\
\hline SP 1 & 0 & 9 & 11 & 6 & 8 & 9 & 8 & 28 & 59 & 3 & 0 & 141 \\
\hline SP 2 & 79 & 0 & 13 & 6 & 9 & 4 & 1 & 6 & 1 & 1 & 0 & 120 \\
\hline SP 3 & 13 & 44 & 0 & 10 & 6 & 9 & 9 & 8 & 5 & 3 & 0 & 107 \\
\hline SP 4 & 6 & 9 & 30 & 0 & 8 & 7 & 8 & 8 & 6 & 5 & 0 & 87 \\
\hline SP 5 & 6 & 13 & 11 & 20 & 0 & 12 & 14 & 19 & 21 & 4 & 0 & 120 \\
\hline SP 6 & 6 & 5 & 7 & 5 & 44 & 0 & 23 & 23 & 9 & 4 & 0 & 126 \\
\hline SP 7 & 6 & 8 & 11 & 11 & 8 & 39 & 0 & 49 & 22 & 2 & 0 & 156 \\
\hline SP 8 & 1 & 0 & 1 & 6 & 9 & 11 & 64 & 0 & 67 & 3 & 0 & 162 \\
\hline "Blank" & 3 & 4 & 1 & 3 & 2 & 4 & 5 & 2 & 2 & 10 & 0 & 36 \\
\hline No response & 17 & 25 & 21 & 16 & 24 & 29 & 21 & 13 & 0 & 1 & 314 & 481 \\
\hline Total & 137 & 117 & 106 & 83 & 118 & 124 & 153 & 156 & 192 & 36 & 314 & 1,536 \\
\hline \multicolumn{13}{|c|}{ Precued ISR } \\
\hline SP 1 & 0 & 1 & 0 & 0 & 0 & 0 & 0 & 0 & 141 & 4 & 0 & 146 \\
\hline SP 2 & 114 & 0 & 5 & 1 & 0 & 0 & 0 & 0 & 5 & 11 & 0 & 136 \\
\hline SP 3 & 6 & 76 & 0 & 8 & 0 & 0 & 1 & 0 & 3 & 16 & 0 & 110 \\
\hline SP 4 & 2 & 17 & 62 & 0 & 1 & 0 & 1 & 0 & 1 & 18 & 0 & 102 \\
\hline SP 5 & 0 & 5 & 10 & 41 & 0 & 5 & 2 & 1 & 0 & 32 & 0 & 96 \\
\hline SP 6 & 2 & 1 & 3 & 9 & 43 & 0 & 3 & 1 & 0 & 25 & 0 & 87 \\
\hline SP 7 & 0 & 1 & 2 & 5 & 9 & 31 & 0 & 9 & 0 & 48 & 0 & 105 \\
\hline SP 8 & 0 & 0 & 0 & 1 & 6 & 12 & 44 & 0 & 1 & 36 & 0 & 100 \\
\hline "Blank" & 20 & 32 & 24 & 29 & 24 & 14 & 5 & 1 & 41 & 182 & 0 & 372 \\
\hline No response & 2 & 3 & 4 & 8 & 13 & 23 & 40 & 24 & 0 & 0 & 165 & 282 \\
\hline Total & 146 & 136 & 110 & 102 & 96 & 85 & 96 & 36 & 192 & 372 & 165 & 1,536 \\
\hline \multicolumn{13}{|c|}{ Postcued ISR } \\
\hline SP 1 & 0 & 1 & 0 & 0 & 0 & 0 & 0 & 0 & 136 & 5 & 0 & 142 \\
\hline SP 2 & 97 & 0 & 3 & 0 & 2 & 2 & 0 & 0 & 2 & 6 & 0 & 112 \\
\hline SP 3 & 9 & 61 & 0 & 2 & 0 & 0 & 1 & 0 & 3 & 21 & 0 & 97 \\
\hline SP 4 & 1 & 6 & 54 & 0 & 2 & 1 & 2 & 0 & 0 & 21 & 0 & 87 \\
\hline SP 5 & 0 & 6 & 9 & 45 & 0 & 4 & 2 & 0 & 3 & 32 & 0 & 101 \\
\hline SP 6 & 1 & 2 & 2 & 6 & 46 & 0 & 4 & 1 & 0 & 25 & 0 & 87 \\
\hline SP 7 & 1 & 1 & 3 & 2 & 8 & 39 & 0 & 5 & 0 & 31 & 0 & 90 \\
\hline SP 8 & 0 & 0 & 1 & 2 & 5 & 9 & 35 & 0 & 0 & 47 & 0 & 99 \\
\hline "Blank" & 31 & 29 & 22 & 25 & 21 & 10 & 3 & 1 & 46 & 247 & 0 & 435 \\
\hline No response & 2 & 6 & 3 & 5 & 17 & 19 & 36 & 31 & 2 & 0 & 165 & 286 \\
\hline Total & 142 & 112 & 97 & 87 & 101 & 84 & 83 & 38 & 192 & 435 & 165 & 1,536 \\
\hline
\end{tabular}

Note-The four subtables show the distribution of transitions of successive pairs of responses (items $n-1$ and $n$ ) across the four experimental conditions (from top to bottom): precued free recall, postcued free recall, precued immediate serial recall (ISR), and postcued ISR. The rows represent the serial position of a word output in output position $n$. The columns represent the serial position of a word output in the immediately preceding output position, $n-1$. These words were the first words that were output on a trial. "Blank" refers to the participant's saying "blank"; "no response" refers to the point at which the participant, having finished recall on a given trial, did not produce any further responses.

from toward the end of the list in free recall. The ISR conditions resulted in far more "blank" responses, and the free recall conditions again resulted in far more responses with negative lag transitions. Nevertheless, in all four conditions, subsequent recalls were most often in a forward serial order. When the frequencies of responses of differ- ent lags were divided by the opportunities to make such responses, it was found that the degree of forward serial recall was strikingly similar across the four conditions.

Finally, there were small (and only sometimes significant) differences in the effect of test expectancy on the two tasks. There was no effect of test expectancy on the analy- 

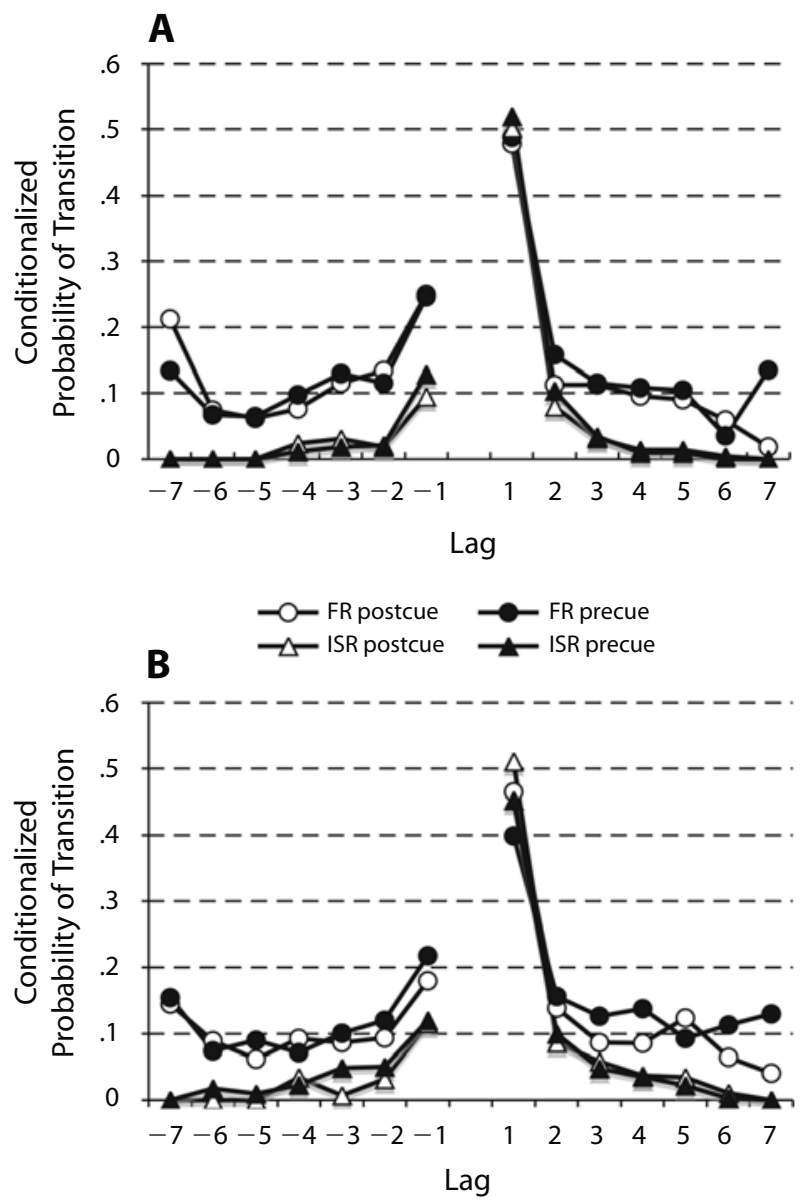

Figure 3. Conditionalized probability of transition data from Experiment 1 (A) and Experiment 2 (B) for each lag value and for each of the four experimental conditions. The lag between a pair of successive responses is calculated by subtracting the serial position of the first word of the pair from the serial position of the second word of the pair. The conditionalized probability of recall is calculated by dividing the actual frequency of making transitions of particular lag values by the opportunity to make such transitions. FR, free recall; ISR, immediate serial recall.

ses of the serial position curves or the slopes of the ISR data. However, there was a nonsignificant trend suggesting more primacy and less recency in the postcued free recall data than in the precued free recall data, and the analysis of the slopes revealed a marginally significant interaction between free recall and test expectancy. In addition, there was a somewhat greater tendency in the free recall postcued condition to initiate output from the beginning of the list (a characteristic output pattern of ISR), relative to the precued free recall condition. This suggests that there was some carryover effects between conditions or some anticipation of an ISR postcue on the free recall postcue conditions.

Overall, our results demonstrate that the U-shaped serial position curves for free recall and the extended primacy with limited recency serial position curves for ISR could be obtained when the two tasks were postcued, suggesting that the differences in the serial position curves in the two tasks are largely characteristic of differences in retrieval, rather than differences resulting from strategic encoding. The data also indicate that the participants had some ability to choose whether to begin their recalls with the first or with later serial positions in the postcued conditions. However, once recall was under way, the degree of serial recall was not significantly greater in ISR than in free recall, suggesting that this aspect of retrieval in ISR was otherwise rather similar to retrieval in free recall.

\section{EXPERIMENT 2}

Experiment 2 aimed to replicate and extend the findings of Experiment 1 using a between-subjects design. One potential concern was that some aspects of the data obtained in Experiment 1 could be attributable to the within-subjects design: There may be carryover effects from one block of trials to another. In order to alleviate this concern, we attempted to replicate Experiment 1 using a between-subjects design. In addition, we also changed the method of responding in Experiment 2. Experiment 1 showed extended primacy in the ISR conditions but no recency. We conjectured two reasons for this finding based on the oral method of responding: (1) The participants' oral recalls could have acted as a stimulus suffix, and (2) the participants may have lost track of the number of responses that they were making, leading to a substantial number of responses that had either more than or fewer than eight items (hence affecting the ISR scoring on the last items). We reasoned that the participants would be in a better position to keep track of their responses if they had to write down their responses in an eight-line response grid while recalling out loud.

Thus, in Experiment 2, there were three groups of participants. One group always knew that they would perform free recall at test, and they constituted the precued free recall condition. A second group always knew that they would perform ISR at test, and they constituted the precued ISR condition. A third group was always postcued after encoding but prior to recall. When the postlist cue indicated "any order," the participants performed free recall (the postcued free recall condition), and when the postlist cue indicated "same order," the participants performed ISR (the postcued ISR condition). If ISR and free recall are normally encoded and retrieved in a similar way, one would expect the results of Experiment 1 to be replicated in Experiment 2.

\section{Method}

Participants. Forty-eight students from the University of Essex participated in this experiment in exchange for $£ 5$. None had taken part in the earlier experiment.

Materials and Apparatus. The materials and apparatus were identical to those in Experiment 1.

Design. The experiment used a mixed-subjects design. For each task, there was a between-subjects independent variable of test expectancy with two levels (precued or postcued), and a withinsubjects independent variable of serial position of the list items with eight levels (SPs 1, 2, 3, 4, 5, 6, 7, or 8).

Procedure. The participants were randomly allocated into three groups of 16 participants. All received a total of 32 trials. The presentation of each trial was as described in Experiment 1, except that one group was instructed to perform only free recall and they always received the precued free recall trials, a second group was instructed to perform only ISR and they always received the precued ISR trials, and a third group was instructed to perform free recall or ISR 
depending on the postlist cue (and thus contributed data to both the postcued free recall and the postcued ISR conditions, respectively).

A final change from Experiment 1 was that the method of responding was changed in this experiment: The participants were required to write down their answers in a numbered eight-line response grid. They were told that in the free recall conditions, they could write down the words on any line that they wished but that in the ISR conditions, they should write their responses in serial order starting from SP 1 to SP 8. The participants had to speak their answers out loud as they wrote them down. They were told that in the ISR conditions, they should say "blank" for words that they could not remember, and they were not allowed to return to earlier serial positions after writing down later responses. A tape recorder was used to record the participants' responses to ensure that they were obeying the instructions.

\section{Results}

The data from 5 of the 512 precued ISR trials and from 8 of the 256 postcued ISR trials were excluded from the analyses because the participants did not write down their responses in a strict forward serial order as instructed. The results for the free recall and remaining ISR trials were analyzed separately, as before.

Free recall. The proportions of words recalled at each serial position for the free recall tasks are shown in Figure 1 B. A $2 \times 8$ mixed-subjects ANOVA with two factors: test expectancy (postcued or precued) and serial position (SPs 1, 2, 3, 4, 5, 6, 7, or 8) revealed a nonsignificant main effect of test expectancy $\left[F(1,30)=0.78, M S_{\mathrm{e}}=0.066, p>\right.$ $.05]$, a significant main effect of serial position $[F(7,210)=$ $\left.28.23, M S_{\mathrm{e}}=0.024, p<.01\right]$, and a nonsignificant interaction $\left[F(7,210)=2.02, M S_{\mathrm{e}}=0.024, p>.05\right]$.

Tukey HSD pairwise comparisons on the significant main effect of serial position revealed significant differences between SP 1 and each of SPs 2-5 (showing significant primacy), between SP 4 and SP 6, and for all pairwise comparisons between SPs 7-8 and SPs 2-6 and between SP 1 and SP 8 (showing significant recency).

ISR. The proportions of words recalled in correct serial order at each serial position in the ISR trials are displayed in Figure 2B. A $2 \times 8$ mixed-subjects ANOVA with two factors, test expectancy (precued or postcued) and serial position (SPs 1, 2, 3, 4, 5, 6, 7, or 8), revealed a nonsignificant main effect of test expectancy $\left[F(1,30)=0.35, M S_{\mathrm{e}}=\right.$ $0.066, p>.05]$, a significant main effect of serial position $\left[F(7,210)=36.84, M S_{\mathrm{e}}=0.024, p<.01\right]$, and a nonsignificant interaction $\left[F(7,210)=1.04, M S_{\mathrm{e}}=0.024, p>.05\right]$.

Tukey HSD pairwise comparisons on the significant main effect of serial position revealed significant differences between all pairwise comparisons involving SPs $1-2$ and SPs 3-8 and between each pairwise comparison involving SP 3 and SPs 4-6 (showing significant primacy, and significant differences between SP 8 and each of SPs 3-7 (showing a significant, although limited, recency advantage).

Output order. Table 3 shows the number of list items recalled in the different output positions. When ISR was precued, the first word outputted was SP 1 on 338 of the possible 507 first responses, $(M=.67)$, and when ISR was postcued, the first output was SP 1 on 163 of the possible 248 first responses $(M=.66)$. In keeping with ISR instructions, the frequencies of words subsequently output are clustered around the leading diagonal, indicating that the participants outputted words more or less accurately in order of their serial position.

In the free recall data sets, there was again some indication of forward order recall starting from SP 1, although this proportion was considerably lower than that for ISR (67 out of 512 possible first responses $[M=.13]$ and 103 out of 256 possible first responses $[M=.40]$ for precued free recall and postcued free recall, respectively). However, in free recall, the participants tended more often to output later list items first. The proportions of trials on which recall was initiated with an item from the second half of the list (SPs 5-8) were 394 out of 512 possible responses $(M=.77)$ for the precued free recall conditions and 138 of 256 possible responses $(M=.54)$ for the postcued free recall conditions, values considerably greater than those for the ISR data.

Table 4 shows the number of list items recalled (other than the first) as a function of their lag. We are again interested in the number of lag +1 responses across the free recall and ISR conditions. These responses are the most frequent in all four conditions, totaling 573 and 365 responses for the free recall precued and free recall postcued conditions, respectively, and 770 and 417 responses for the ISR precued and free recall postcued conditions, respectively. Once again, we can see that the number of negative lags is far greater in the free recall than in the ISR conditions.

The greatly increased values in the precued conditions is of course expected, given that there was twice as many trials in the precued conditions as in the postcued conditions. To accurately compare these values, we must again take into account the number of transitions made at different lags and also the opportunity to make transitions of different lags. We calculated response probabilities for these data in the same way as in Experiment 1. Figure 3B shows the response probabilities plotted for each lag and for each of the four conditions. All response lag functions show that the most frequent transition between responses was that of lag +1 . An independent samples $t$ test revealed that there was no significant difference between the mean proportion of lag +1 responses for the precued free recall and the precued ISR conditions $[t(30)=1.51, p>$ $.05]$. However, a related samples $t$ test revealed that there was a significant difference between the mean proportion of lag +1 responses for the postcued free recall and the postcued ISR conditions $[t(15)=2.62, p<.05]$. These analyses show that there was a comparable tendency to output responses in a forward order in the two precued conditions, once the opportunity to respond in a forward order was controlled for, but that there was an increased tendency to output in a forward serial order in the postcued ISR condition, relative to the postcued free recall condition.

\section{Discussion}

There are three main findings from Experiment 2. First, as in Experiment 1, different serial position curves were obtained with the free recall and ISR tasks. The serial position curve of the precued free recall condition was U-shaped, whereas that obtained in the precued ISR condition showed 
Table 3

Data From Experiment 2

\begin{tabular}{|c|c|c|c|c|c|c|c|c|c|}
\hline \multirow[b]{2}{*}{ Serial Position } & \multicolumn{8}{|c|}{ Output Position } & \multirow[b]{2}{*}{ Total } \\
\hline & 1 & 2 & 3 & 4 & 5 & 6 & 7 & 8 & \\
\hline \multicolumn{10}{|c|}{ Precued Free Recall } \\
\hline SP 1 & 67 & 35 & 50 & 46 & 71 & 25 & 9 & 2 & 305 \\
\hline SP 2 & 14 & 40 & 38 & 47 & 52 & 29 & 13 & 4 & 237 \\
\hline SP 3 & 15 & 30 & 47 & 49 & 51 & 29 & 10 & 2 & 233 \\
\hline SP 4 & 18 & 27 & 47 & 50 & 44 & 28 & 12 & 3 & 229 \\
\hline SP 5 & 62 & 44 & 59 & 53 & 27 & 18 & 6 & 1 & 270 \\
\hline SP 6 & 40 & 98 & 81 & 61 & 19 & 7 & 7 & 2 & 315 \\
\hline SP 7 & 86 & 136 & 99 & 53 & 18 & 9 & 1 & 0 & 402 \\
\hline SP 8 & 206 & 94 & 62 & 62 & 29 & 8 & 4 & 1 & 466 \\
\hline "Blank" & 4 & 7 & 16 & 14 & 4 & 3 & 1 & 0 & 49 \\
\hline No response & 0 & 1 & 13 & 77 & 197 & 356 & 449 & 497 & 1,590 \\
\hline Total & 512 & 512 & 512 & 512 & 512 & 512 & 512 & 512 & 4,096 \\
\hline \multicolumn{10}{|c|}{ Postcued Free Recall } \\
\hline SP 1 & 103 & 12 & 21 & 19 & 11 & 5 & 3 & 1 & 175 \\
\hline SP 2 & 2 & 71 & 19 & 17 & 14 & 6 & 3 & 1 & 133 \\
\hline SP 3 & 4 & 17 & 59 & 15 & 12 & 11 & 4 & 0 & 122 \\
\hline SP 4 & 6 & 7 & 22 & 45 & 20 & 9 & 1 & 1 & 111 \\
\hline SP 5 & 17 & 17 & 23 & 29 & 25 & 4 & 1 & 0 & 116 \\
\hline SP 6 & 16 & 34 & 29 & 27 & 11 & 12 & 4 & 0 & 133 \\
\hline SP 7 & 41 & 45 & 36 & 22 & 17 & 7 & 3 & 2 & 173 \\
\hline SP 8 & 64 & 42 & 31 & 28 & 22 & 12 & 5 & 2 & 206 \\
\hline "Blank" & 3 & 11 & 9 & 12 & 7 & 3 & 1 & 0 & 46 \\
\hline No response & 0 & 0 & 7 & 42 & 117 & 187 & 231 & 249 & 833 \\
\hline Total & 256 & 256 & 256 & 256 & 256 & 256 & 256 & 256 & 2,048 \\
\hline \multicolumn{10}{|c|}{ Precued ISR } \\
\hline SP 1 & 338 & 24 & 4 & 4 & 0 & 2 & 0 & 0 & 372 \\
\hline SP 2 & 12 & 249 & 8 & 7 & 2 & 5 & 0 & 1 & 284 \\
\hline SP 3 & 4 & 31 & 170 & 10 & 7 & 5 & 1 & 1 & 229 \\
\hline SP 4 & 6 & 15 & 46 & 123 & 22 & 4 & 4 & 3 & 223 \\
\hline SP 5 & 12 & 10 & 33 & 48 & 89 & 25 & 9 & 4 & 230 \\
\hline SP 6 & 3 & 9 & 18 & 36 & 43 & 100 & 21 & 7 & 237 \\
\hline SP 7 & 1 & 0 & 14 & 14 & 33 & 63 & 128 & 12 & 265 \\
\hline SP 8 & 0 & 0 & 1 & 14 & 29 & 31 & 40 & 169 & 284 \\
\hline "Blank" & 131 & 168 & 201 & 229 & 215 & 142 & 84 & 0 & 1,170 \\
\hline No response & 0 & 1 & 12 & 22 & 67 & 130 & 220 & 310 & 762 \\
\hline Total & 507 & 507 & 507 & 507 & 507 & 507 & 507 & 507 & 4,056 \\
\hline \multicolumn{10}{|c|}{ Postcued ISR } \\
\hline SP 1 & 163 & 4 & 0 & 1 & 2 & 1 & 0 & 0 & 171 \\
\hline SP 2 & 4 & 126 & 4 & 1 & 0 & 1 & 0 & 0 & 136 \\
\hline SP 3 & 5 & 13 & 78 & 6 & 4 & 2 & 2 & 0 & 110 \\
\hline SP 4 & 2 & 8 & 20 & 53 & 10 & 5 & 2 & 0 & 100 \\
\hline SP 5 & 2 & 6 & 17 & 15 & 42 & 10 & 5 & 4 & 101 \\
\hline SP 6 & 1 & 7 & 2 & 13 & 14 & 56 & 13 & 5 & 111 \\
\hline SP 7 & 1 & 2 & 5 & 6 & 15 & 21 & 74 & 6 & 130 \\
\hline SP 8 & 0 & 0 & 3 & 4 & 6 & 6 & 17 & 118 & 154 \\
\hline "Blank" & 69 & 80 & 113 & 131 & 114 & 85 & 52 & 0 & 644 \\
\hline No response & 1 & 2 & 6 & 18 & 41 & 61 & 83 & 115 & 327 \\
\hline Total & 248 & 248 & 248 & 248 & 248 & 248 & 248 & 248 & 1,984 \\
\hline
\end{tabular}

Note-The four subtables show the distribution of words recalled by serial position and output position for the four experimental conditions (from top to bottom): precued free recall, postcued free recall, precued ISR, and postcued ISR. "Blank" refers to the participant's saying "blank"; "no response" refers to the point at which the participant, having finished recall on a given trial, did not produce any further responses.

extended primacy and only limited recency. In contrast with Experiment 1, the ISR serial position curves in Experiment 2 showed a significant but limited recency advantage. We attribute this limited recency (which is characteristic of ISR under these conditions) to the use of written responses in the response grid, which helped the participants keep track of the number of responses that they had made. That the recency was not more marked (given that the stimuli were read aloud) may be because the oral responses continued to provide something of a stimulus suffix.

Second, as in Experiment 1, the serial position curves from the postcued conditions closely resembled those from the precued conditions. That these results were obtained using a between-subjects manipulation of task and cuing condition suggests that the methods of encoding for free recall and ISR are normally highly similar and that 
Table 4

Data From Experiment 2

\begin{tabular}{|c|c|c|c|c|c|c|c|c|c|c|c|c|}
\hline \multirow[b]{2}{*}{$\begin{array}{l}\text { Serial Position of } \\
\text { Output Position } n\end{array}$} & \multicolumn{11}{|c|}{ Serial Position of Prior Item (Output Position $n-1$ ) } & \multirow[b]{2}{*}{ Total } \\
\hline & 1 & 2 & 3 & 4 & 5 & 6 & 7 & 8 & - & Blank & $\begin{array}{c}\text { No } \\
\text { Response }\end{array}$ & \\
\hline \multicolumn{13}{|c|}{ Precued Free Recall } \\
\hline SP 1 & 0 & 33 & 34 & 27 & 17 & 31 & 26 & 64 & 67 & 6 & 0 & 305 \\
\hline SP 2 & 99 & 0 & 27 & 15 & 16 & 15 & 16 & 29 & 14 & 6 & 0 & 237 \\
\hline SP 3 & 38 & 51 & 0 & 22 & 23 & 17 & 17 & 45 & 15 & 5 & 0 & 233 \\
\hline SP 4 & 27 & 26 & 37 & 0 & 24 & 19 & 35 & 36 & 18 & 7 & 0 & 229 \\
\hline SP 5 & 27 & 19 & 17 & 33 & 0 & 34 & 29 & 46 & 62 & 3 & 0 & 270 \\
\hline SP 6 & 12 & 19 & 18 & 22 & 85 & 0 & 54 & 58 & 40 & 7 & 0 & 315 \\
\hline SP 7 & 13 & 10 & 18 & 17 & 27 & 106 & 0 & 118 & 86 & 7 & 0 & 402 \\
\hline SP 8 & 5 & 10 & 12 & 15 & 17 & 33 & 162 & 0 & 206 & 6 & 0 & 466 \\
\hline "Blank" & 6 & 3 & 5 & 5 & 6 & 1 & 8 & 9 & 4 & 2 & 0 & 49 \\
\hline No response & 76 & 62 & 63 & 70 & 54 & 57 & 55 & 60 & 0 & 0 & 1,093 & 1,590 \\
\hline Total & 303 & 233 & 231 & 226 & 269 & 313 & 402 & 465 & 512 & 49 & 1,093 & 4,096 \\
\hline \multicolumn{13}{|c|}{ Postcued Free Recall } \\
\hline SP 1 & 0 & 13 & 7 & 4 & 9 & 5 & 12 & 19 & 103 & 3 & 0 & 175 \\
\hline SP 2 & 93 & 0 & 8 & 3 & 2 & 4 & 8 & 8 & 2 & 5 & 0 & 133 \\
\hline SP 3 & 12 & 59 & 0 & 9 & 3 & 12 & 10 & 9 & 4 & 4 & 0 & 122 \\
\hline SP 4 & 5 & 14 & 39 & 0 & 7 & 7 & 5 & 21 & 6 & 7 & 0 & 111 \\
\hline SP 5 & 9 & 8 & 10 & 24 & 0 & 12 & 11 & 22 & 17 & 3 & 0 & 116 \\
\hline SP 6 & 13 & 6 & 8 & 7 & 34 & 0 & 18 & 26 & 16 & 5 & 0 & 133 \\
\hline SP 7 & 4 & 6 & 8 & 12 & 22 & 40 & 0 & 36 & 41 & 4 & 0 & 173 \\
\hline SP 8 & 4 & 8 & 15 & 10 & 9 & 14 & 76 & 0 & 64 & 6 & 0 & 206 \\
\hline "Blank" & 8 & 2 & 3 & 3 & 5 & 2 & 1 & 10 & 3 & 9 & 0 & 46 \\
\hline No response & 26 & 16 & 24 & 38 & 25 & 37 & 30 & 53 & 0 & 0 & 584 & 833 \\
\hline Total & 174 & 132 & 122 & 110 & 116 & 133 & 171 & 204 & 256 & 46 & 584 & 2,048 \\
\hline \multicolumn{13}{|c|}{ Precued ISR } \\
\hline SP 1 & 0 & 10 & 5 & 2 & 2 & 1 & 1 & & 338 & 13 & 0 & 372 \\
\hline SP 2 & 228 & 0 & 8 & 2 & 5 & 3 & 1 & 1 & 12 & 24 & 0 & 284 \\
\hline SP 3 & 24 & 123 & 0 & 17 & 5 & 5 & 2 & 1 & 4 & 48 & 0 & 229 \\
\hline SP 4 & 16 & 25 & 86 & 0 & 13 & 4 & 11 & 1 & 6 & 61 & 0 & 223 \\
\hline SP 5 & 9 & 16 & 30 & 52 & 0 & 10 & 7 & 1 & 12 & 93 & 0 & 230 \\
\hline SP 6 & 5 & 10 & 11 & 23 & 86 & 0 & 16 & 8 & 3 & 75 & 0 & 237 \\
\hline SP 7 & 1 & 11 & 5 & 14 & 19 & 81 & 0 & 15 & 1 & 118 & 0 & 265 \\
\hline SP 8 & 0 & 1 & 4 & 14 & 8 & 27 & 114 & 0 & 0 & 116 & 0 & 284 \\
\hline "Blank" & 86 & 76 & 66 & 62 & 59 & 41 & 21 & 6 & 131 & 622 & 0 & 1,170 \\
\hline No response & 3 & 11 & 13 & 34 & 29 & 58 & 80 & 82 & 0 & 0 & 452 & 762 \\
\hline Total & 372 & 283 & 228 & 220 & 226 & 230 & 253 & 115 & 507 & 1,170 & 452 & 4,056 \\
\hline \multicolumn{13}{|c|}{ Postcued ISR } \\
\hline SP 1 & 0 & 2 & 0 & 1 & 1 & 0 & 0 & 0 & 163 & 4 & 0 & 171 \\
\hline SP 2 & 119 & 0 & 3 & 0 & 0 & 2 & 0 & 0 & 4 & 8 & 0 & 136 \\
\hline SP 3 & 12 & 68 & 0 & 6 & 5 & 1 & 0 & 0 & 5 & 13 & 0 & 110 \\
\hline SP 4 & 1 & 15 & 42 & 0 & 4 & 2 & 0 & 3 & 2 & 31 & 0 & 100 \\
\hline SP 5 & 5 & 7 & 3 & 27 & 0 & 11 & 2 & 0 & 2 & 44 & 0 & 101 \\
\hline SP 6 & 8 & 2 & 8 & 4 & 36 & 0 & 9 & 0 & 1 & 43 & 0 & 111 \\
\hline SP 7 & 1 & 3 & 7 & 8 & 10 & 46 & 0 & 3 & 1 & 51 & 0 & 130 \\
\hline SP 8 & & 2 & 2 & 1 & 6 & 11 & 79 & 0 & 0 & 53 & 0 & 154 \\
\hline "Blank" & 25 & 33 & 37 & 38 & 20 & 15 & 9 & 1 & 69 & 397 & 0 & 644 \\
\hline No response & 0 & 4 & 8 & 15 & 15 & 18 & 25 & 29 & 1 & 0 & 212 & 327 \\
\hline Total & 171 & 136 & 110 & 100 & 97 & 106 & 124 & 36 & 248 & 644 & 212 & 1,984 \\
\hline
\end{tabular}

Note-The four subtables show the distribution of transitions of successive pairs of responses (items $n-1$ and $n$ ) across the four experimental conditions (from top to bottom): precued free recall, postcued free recall, precued immediate serial recall (ISR), and postcued ISR. The rows represent the serial position of a word output in output position $n$. The columns represent the serial position of a word output in the immediately preceding output position, $n-1$. A dash indicates that there was no preceding list item. These words were the first words that were output on a trial. "Blank" refers to the participant's saying "blank"; "no response" refers to the point at which the participant, having finished recall on a given trial, did not produce any further responses.

the differences in the serial position curves between the two tasks cannot be attributed to substantial differences in strategic encoding.

Third, as in Experiment 1, the analyses of output order revealed that the participants initiated recall from the end of the list in free recall but from the start of the list in ISR. The ISR conditions again resulted in far more "blank" responses, and the free recall conditions again resulted in far more responses with negative lag transitions. In all four conditions, the participants tended to make a greater pro- 
portion of responses in a forward serial order than any other transition. In the precued conditions (in which the participants performed only one of the two tasks), there was no significant difference between the proportion of responses made in the forward serial order in the precued free recall and precued ISR conditions. However, contrary to Experiment 1 , a significantly greater proportion of responses were made in the forward serial order in the postcued ISR condition, relative to the postcued free recall condition.

\section{Post Hoc Analyses}

A final set of analyses was conducted to examine the effects of test expectancy on the shapes of the serial position curves for free recall and ISR across the two experiments. The primary issue was that there appeared to be a replicable pattern of data in the free recall data of Experiments 1 and 2: When precued, there seemed to be increased recency and decreased primacy, relative to postcued free recall performance. In each case, the interaction failed to reach significance [for Experiment $1, F(7,161)=1.80$, $p>.05$; for Experiment $2, F(7,210)=2.02, p>.05]$. However, it was possible that a combined analysis across both experiments might yield a significant effect that would merit explanation. A secondary motivation was that it appeared that the free recall and ISR conditions gave rise to serial position curves with different shapes: significant primacy and recency for free recall, and extended primacy with little or no recency for ISR. However, to date the analyses of free recall and ISR have been performed separately, so that no direct comparisons of the shapes of the curves of the two tasks have been made.

Our task of combining across the experiments was made more difficult, however, because the critical comparisons between tasks and test expectancies were within-subjects factors in Experiment 1 but between-subjects factors in Experiment 2. In order to circumvent this problem, we presented the data for analysis as if task and test expectancy were entirely between-subjects variables so that there were 40 participants in each of four conditions (free recall precued, free recall postcued, ISR precued, and ISR postcued).

A 2 (task) $\times 2$ (cue) $\times 8$ (serial position) mixed ANOVA was performed on this combined data set, which yielded a highly significant main effect of task $[F(1,156)=134.0$, $\left.M S_{\mathrm{e}}=19.84, p<.0001\right]$ - showing free recall performance to be superior to ISR - a nonsignificant main effect of cue $[F(1,156)<1, p>.05]$, and a highly significant main effect of serial position $\left[F(7,1092)=52.17, M S_{\mathrm{e}}=\right.$ $1.74, p<.0001]$. The two-way interaction between task and cue was not significant $[F(1,156)<1, p>.05]$, nor was the two-way interaction between cue and serial position $[F(1,156)<1, p>.05]$. However, the two-way interaction between task and serial position was highly significant $\left[F(7,1092)=57.16, M S_{\mathrm{e}}=1.903, p<.0001\right]$, and this showed that recall in free recall was superior to recall in ISR in SPs 3-8, but not in SPs 1-2. The three-way interaction between task, cue, and serial position was also significant $\left[F(7,1092)=2.61, M S_{\mathrm{e}}=0.088, p<.05\right]$. There were significant simple main effects of task for SPs 5-8 for both the precued and the postcued conditions, indicating the superior recency advantage in free recall, relative to ISR. There were no significant simple main effects of cue at any level of task or serial position, but there were significant simple main effects of serial position for each of the four task $\times$ cue conditions.

The lack of any effect of cue type was surprising given the apparent replicability of the data in the two experiments, and so a further 2 (cue) $\times 8$ (serial position) mixed ANOVA was performed using only the free recall data combined across both experiments. This revealed a nonsignificant main effect of cue $[F(1,78)<1, p>.05]$, a significant main effect of serial position $\left[F(7,546)=46.88, M S_{\mathrm{e}}=\right.$ $1.61, p<.0001]$, and a significant interaction $[F(7,546)=$ $\left.2.59, M S_{\mathrm{e}}=0.089, p<.05\right]$. Simple main effects revealed significant simple main effects of serial position for both cuing conditions $(p<.0001)$ but a significant simple main effect of cue only at SP $8(p=.0498)$, although the simple main effect of cue at SPs 1 and 7 also almost reached significance ( $p \mathrm{~s}=.0693$ and .0821 , respectively).

Together, these combined analyses reveal that there were different-shaped serial position curves for free recall and ISR, and similar-shaped, although not exactly identical, serial position curves for the precued and postcued free recall conditions. That is, there was some indication that there was greater recency and reduced primacy in the precued free recall condition than in the postcued free recall condition.

\section{GENERAL DISCUSSION}

When free recall and ISR were performed under identical methodological conditions, we obtained serial position curves that were indicative of the method of testing that was used: The serial position curves for free recall were U-shaped, whereas those for ISR showed extended primacy with little or no recency.

Taken separately, the data for each task appear to be consistent with an STS mechanism, whether it be an STS buffer for the recency effect in free recall (e.g., Atkinson \& Shiffrin, 1971; Davelaar et al., 2005; Glanzer, 1972; Murdock, 1967) or an STS mechanism for the primacy curves in ISR (e.g., Baddeley et al., 1975; Burgess \& Hitch, 1999; Henson, 1998; Miller, 1956; Page \& Norris, 1998).

Taken together, however, the data directly exemplify the tension that exists in STS explanations of the two tasks. One might reasonably assume that the lists of words presented in the different conditions of our experiments might be encoded and retrieved using similar memory mechanisms. However, in line with our explanations in the introduction, the data of Baddeley and Hitch (1974, 1977) and Bhatarah et al. (2006) necessitate that any STS mechanisms identified in ISR cannot be contributing to STS phenomena in free recall and vice versa.

In fact, there was little indication that serial recall was a specialist STS mechanism used exclusively in ISR. Rather, forward serial recall was prevalent across all four conditions of each experiment, even in free recall where serial recall was not a requirement. Although there was some indication that the proportion of responses output in forward serial order was greater for ISR than for free recall, these differences reached significance only in the postcued conditions of Experiment 2. 
The prevalence of recall in forward serial order across all conditions of both experiments suggests that forward serial recall may be a general property of memory, a finding consistent with data from recent studies of free recall (Bhatarah et al., 2006; Howard \& Kahana, 1999, 2002a, 2002b; Kahana, 1996; Laming, 1999, 2006; Ward et al., 2003), free reconstruction of order (Lewandowsky et al., in press; Tan \& Ward, 2007), and serial recall (Klein et al., 2005; Nairne, 1992, 2002; Nairne \& Neath, 2001). Our work perhaps most closely complements that performed by Klein et al. (2005). Whereas we have demonstrated that lag +1 responses are similarly prevalent in free recall and ISR, using lists of 8 words, Klein et al. (2005) showed that lag +1 responses were also the most frequent responses for the first trials in both serial learning and free recall learning conditions with longer lists of 19 words. Klein et al.'s demonstration shows that the similarity in forward serial recall across tasks is not limited to short lists of only eight items but is apparent at the longer list lengths more frequently used in free recall.

The clearest and most obvious differences between recall in the two tasks were (1) that recall tended to begin from the start of the list in ISR but from toward the end of the list in free recall and (2) that participants more often said "blank" in ISR and more often said a word from a negative lag in free recall. These findings suggest a degree of strategic flexibility on the part of the participant (at least, in the postcued conditions). It would seem that participants have at least some capacity to choose whether to start recall from toward the start or toward the end of the list and are able to edit their responses to say "blank" in the ISR conditions, when perhaps a word from an earlier serial position (with a negative lag) might be output in the free recall conditions.

The data also suggest that the two tasks were encoded in similar ways. The serial position curves for the postcued conditions broadly resembled the serial position curves for the precued conditions, indicating that the basic shapes of these serial position curves had little to do with strategic encoding with task-specific mechanisms. We acknowledge, however, that there do appear to be some minor differences between postcued and precued performance. There is a slight tendency for the free recall data to show more primacy and less recency in the postcued conditions than in the precued conditions, and there is a slight tendency for the ISR data to show more recency and less primacy in the postcued conditions than in the precued conditions. This suggests that there may be some slight differences between encoding or retrieval strategies in the precued and postcued conditions, an argument supported by the greater tendency for participants to initiate recall at SP 1 under postcued free recall, as compared with precued free recall.

Our preferred explanation for these data is that the same general memory mechanisms underpin both free recall and ISR. We hypothesize that the mechanisms are not specialist short-term memory mechanisms because of the difficulties with common STS mechanisms for free recall and ISR raised in the introduction and elsewhere (Ward, 2001). Rather, the general memory mechanisms are (1) recency sensitive (based on participants' preference to start recall at the end of the list when they are free to choose where to start) and (2) forward ordered (once recall is initiated there is a tendency for forward serial recall in all conditions). Some general models, such as the TCM (Howard \& Kahana, 2002a) readily account for both these empirical phenomena as general properties of encoding in memory, whereas others, such as SIMPLE (Brown et al., 2007; Neath \& Brown, 2006), appear to require both temporal and positional codes. Interestingly, a combination of recency and forward serial recall has also been recently proposed to account for the rehearsal and recall data in free recall (Laming, 2006). General memory mechanisms can readily explain how participants can make use of the ISR or free recall postcue: The words are encoded into and retrieved from the same memory system in the two tasks, and there are relatively minor differences in any strategic differences that arise through different test expectancies.

In summary, this research examined the similarities between free recall and ISR. Our findings indicate (1) that the shapes of the serial position curves are different for free recall and ISR, (2) that the shapes of the serial position curves are relatively unaffected by advance warning of the type of test to be performed, and (3) that the degree of forward serial recall is reasonably similar across all conditions. Our preferred explanation is that both tasks use the same memory mechanisms and that differences in the shapes of the serial position curves reflect differences in the scoring system and the output order of recall.

\section{AUTHOR NOTE}

Experiment 1 was conducted as part of the Ph.D. thesis of the first author (supported by ESRC Research Studentship R42200134058) under the supervision of the second author. Experiment 2 was conducted by the third author as part of ESRC Research Grant R000239674, awarded to the second author. Correspondence concerning this article should be addressed to P. Bhatarah, Department of Psychology, London Metropolitan University, London E1 7NT, England (e-mail: p.bhatarah@londonmet.ac.uk).

\section{REFERENCES}

Atkinson, R. C., \& Shiffrin, R. M. (1971). The control of short-term memory. Scientific American, 225, 82-90.

Baddeley, A. D., \& Hitch, G. J. (1974). Working memory. In G. A. Bower (Ed.), Recent advances in learning and motivation (Vol. 8., pp. 47-90). New York: Academic Press.

BAdDeley, A. D., \& Hitch, G. J. (1977). Recency re-examined. In S. Dornic (Ed.), Attention and performance VI (pp. 647-667). Hillsdale, NJ: Erlbaum.

Baddeley, A. D., Thomson, N., \& Buchanan, M. (1975). Word length and the structure of short-term memory. Journal of Verbal Learning \& Verbal Behavior, 14, 575-589.

Bhatarah, P., WARD, G., \& TAN, L. (2006). Examining the relationship between immediate serial recall and free recall: The effect of concurrent task performance. Journal of Experimental Psychology: Learning, Memory, \& Cognition, 32, 215-229.

Brown, G. D. A., Morin, C., \& Lewandowsky, S. (2006). Evidence for time-based models of free recall. Psychonomic Bulletin \& Review, 13, 717-723.

Brown G. D. A., Neath, I., \& Chater, N. (2007). A temporal ratio model of memory. Psychological Review, 114, 539-576.

Burgess, N., \& Hitch, G. (1992). Toward a network model of the articulatory loop. Journal of Memory \& Language, 31, 429-460.

Burgess, N., \& Hitch, G. (1999). Memory for serial order: A network 
model of the phonological loop and its timing. Psychological Review, 106, 551-581.

Crowder, R. G. (1982). The demise of short-term memory. Acta Psychologica, 50, 291-323.

Crowder, R. G. (1993). Short-term memory: Where do we stand? Memory \& Cognition, 21, 142-145.

Crowder, R. G., \& Neath, I. (1991). The microscope metaphor in human memory. In W. E. Hockley and S. Lewandowsky (Eds.), Relating theory and data: Essays on human memory in honor of Bennet B. Murdock (pp. 111-126). Hillsdale, NJ: Erlbaum.

Davelaar, E. J., Goshen-Gottstein, Y., Ashkenazi, A., Haarmann, H. J., \& UsHeR, M. (2005). The demise of short-term memory revisited: Empirical and computational investigations of recency effects. Psychological Review, 112, 3-42.

Friendly, M., Franklin, P. E., Hoffman, D., \& Rubin, D. C. (1982). The Toronto Word Pool: Norms for imagery, concreteness, orthographic variables, and grammatical usage for 1,080 words. Behavior Research Methods \& Instrumentation, 14, 375-399.

Glanzer, M. (1972). Storage mechanisms in recall. In G. H. Bower (Ed.), The psychology of learning and motivation: Advances in research and theory (Vol. 5, pp. 129-193). New York: Academic Press.

GLENBERG, A. M. (1984). A retrieval account of the long-term modality effect. Journal of Experimental Psychology: Learning, Memory, \& Cognition, 10, 16-31.

Glenberg, A. M. (1987). Temporal context and recency. In D. S. Gorfein \& R. R. Hoffman (Eds.), Memory and learning: The Ebbinghaus Centennial Conference (pp. 173-190). Hillsdale, NJ: Erlbaum.

Glenberg, A. M., Bradley, M. M., Stevenson, J. A., Kraus, T. A., TKaChUK, M. J., GretZ, A. L., ET AL. (1980). A two-process account of long-term serial position effects. Journal of Experimental Psychology: Human Learning \& Memory, 6, 355-369.

Henson, R. N. A. (1998). Short-term memory for serial order: The start-end model of serial recall. Cognitive Psychology, 36, 73-137.

Howard, M. W., \& KaHANA, M. J. (1999). Contextual variability and serial position effects in free recall. Journal of Experimental Psychology: Learning, Memory, \& Cognition, 25, 923-941.

Howard, M. W., \& Kahana, M. J. (2002a). A distributed representation of temporal context. Journal of Mathematical Psychology, 46, 269-299.

HowaRD, M. W., \& KahanA, M. J. (2002b). When does semantic similarity help episodic retrieval? Journal of Memory \& Language, 46, 85-98.

Kahana, M. J. (1996). Associative retrieval processes in free recall. Memory \& Cognition, 24, 103-109.

Kahana, M. J. (2002). Associative symmetry and memory theory. Memory \& Cognition, 30, 823-840.

Kahana, M. J., \& Caplan, J. B. (2002). Associative asymmetry in probed recall of serial lists. Memory \& Cognition, 30, 841-849.

Klein, K. A., AdDis, K. M., \& Kahana, M. J. (2005). A comparative analysis of serial and free recall. Memory \& Cognition, 33, 833-839.

LAMING, D. (1999). Testing the idea of distinct storage mechanisms in memory. International Journal of Psychology, 34, 419-426.

LAMING, D. (2006). Predicting free recalls. Journal of Experimental Psychology: Learning, Memory, \& Cognition, 32, 1146-1163.

Lewandowsky, S., Brown, G. D. A., Wright, T., \& Nimmo, L. M. (2006). Timeless memory: Evidence against temporal distinctiveness models of short-term memory for serial order. Journal of Memory \& Language, 54, 20-38.

Lewandowsky, S., Duncan, M., \& Brown, G. D. A. (2004). Time does not cause forgetting in short-term serial recall. Psychonomic Bulletin \& Review, 11, 771-790.

Lewandowsky, S., Nimmo, L. M., \& Brown, G. D. A. (in press). When temporal isolation benefits memory for serial order. Journal of Memory \& Language.

Miller, G. A. (1956). The magic number seven, plus or minus two: Some limits on our capacity for processing information. Psychological Review, 63, 81-93.

MuRdOCK, B. B., JR. (1967). Recent developments in short-term memory. British Journal of Psychology, 58, 421-433.

NaIRne, J. S. (1992). The loss of positional certainty in long-term memory. Psychological Science, 3, 199-202.

NAIRNE, J. S. (2002). Remembering over the short-term: The case against the standard model. Annual Review of Psychology, 53, 53-81.

NaIRne, J. S., \& NeATH, I. (2001). Long-term memory span. Behavioral \& Brain Sciences, 24, 134-135.

Neath, I., \& Brown, G. D. A. (2006). SIMPLE: Further applications of a local distinctiveness model of memory. In B. H. Ross (Ed.), The psychology of learning and motivation (Vol. 46, pp. 201-243). San Diego: Academic Press.

Neath, I., \& Crowder, R. G. (1990). Schedules of presentation and temporal distinctiveness in human memory. Journal of Experimental Psychology: Learning, Memory, \& Cognition, 16, 316-327.

Nimmo, L. M., \& LewandowsKy, S. (2005). From brief gaps to very long pauses: Temporal isolation does not benefit serial recall. Psychonomic Bulletin \& Review, 12, 999-1004.

Nimmo, L. M., \& LewandowsKy, S. (2006). Distinctiveness revisited: Unpredictable temporal isolation does not benefit short-term serial recall of heard or seen events. Memory \& Cognition, 34, 1368-1375.

PAGE, M. P. A., \& NorRIS, D. (1998). The primacy model: A new model of immediate serial recall. Psychological Review, 105, 761-781.

Rizzuto, D. S., \& Kahana, M. J. (2001). An autoassociative neural network model of paired-associate learning. Neural Computation, 13, 2075-2092.

TAN, L. \& WARD, G. (2000). A recency-based account of primacy effects in free recall. Journal of Experimental Psychology: Learning, Memory, \& Cognition, 26, 1589-1625.

TAN, L., \& WARD, G. (2007). Output order in immediate serial recall. Memory \& Cognition, 35, 1093-1106.

WARD, G. (2001). A critique of the working memory model. In J. Andrade (Ed.), Working memory in perspective (pp. 219-239). Hove, U.K.: Psychology Press.

WARD, G., \& TAN, L. (2004). The effect of the length of to-be-remembered lists and intervening lists on free recall: A re-examination using overt rehearsal. Journal of Experimental Psychology: Learning, Memory, \& Cognition, 30, 1196-1210.

Ward, G., Woodward, G., Stevens, A., \& Stinson, C. (2003). Using overt rehearsals to explain word frequency effects in free recall. Journal of Experimental Psychology: Learning, Memory, \& Cognition, 29, 186-210.

Waugh, N. C., \& Norman, D. A. (1965). Primary memory. Psychological Review, 72, 89-104. 
APPENDIX

A worked example will help explain how these recall probabilities are calculated for each lag. Imagine that a participant received the list FATHER WINTER CHAPEL VOYAGE BANNER ABSENCE SORROW LOVER but recalled FATHER CHAPEL WINTER VOYAGE "blank" ABSENCE SORROW. In this example, the participant recalled words from SPs 1, $3,2,4$, "blank," 6 , and 7 in that order and so made responses with lag transitions of $+2,-1,+2$, incalculable, incalculable, and +1 , respectively.

However, as Table A1 shows, there were opportunities to make many alternative lag transitions in this sequence. After the first response (FATHER), the lag transition could have been +1 (WINTER), +2 (CHAPEL, which was actually output next), +3 (VOYAGE), +4 (BANNER), +5 (ABSENCE), +6 (SORROW), or +7 (LOVER). After the second response (CHAPEL), the lag transition could have been -1 (WINTER, which was actually output next), +1 (VOYAGE), +2 (BANNER), +3 (ABSENCE), + 4 (SORROW), or +5 (LOVER), but not -2 (FATHER), since this word had already been recalled. After the third response (WINTER), the lag transition could have been +2 (VOYAGE, which was actually output), +3 (BANNER), +4 (ABSENCE), +5 (SORROW), or +6 (LOVER), but not -1 (FATHER) or +1 (CHAPEL), since these had already been recalled. After the fourth response (VOYAGE), the participant said "blank," but he or she had the opportunity to recall words from transition lag +1 (BANNER), +2 (ABSENCE), +3 (SORROW), or +4 (LOVER), but not -3 (FATHER), -2 (WINTER), or -1 (CHAPEL), since these words had been output earlier. After the fifth response ("blank"), the word ABSENCE was output, but no lag values could be calculated for this or alternative responses. After the sixth response (ABSENCE), the lag transition could have been -1 (BANNER), +1 (SORROW, which was output next), or +2 (LOVER). After the seventh and final response, there was an opportunity to recall words from lag transitions -2 (BANNER) or +1 (LOVER), but no correct word was recalled.

Note that we cannot calculate lag transitions for the first response in a trial, nor for any response that immediately followed a "blank." For each participant and for each lag, we calculated a recall probability in which the frequency with which a lag transition was made was divided by the frequency with which a lag transition could have been made.

On the basis of this single trial, it would be impossible to calculate recall probabilities (see Table A1) for lag values of -3 or less, since there was no opportunity to do so, but the probabilities for lag values -2 through +7 , would be $.00, .50, .20, .40, .00, .00, .00, .00$, and .00 , respectively.

Table A1

An Example Showing How the Recall Probabilities Are Calculated for Each Lag Value

\begin{tabular}{cccc}
\multicolumn{5}{c}{ Calculated for Each Lag Value } \\
\hline \multicolumn{5}{c}{$\begin{array}{c}\text { Actual } \\
\text { Tag }\end{array}$} & $\begin{array}{c}\text { Opportunities } \\
\text { to Make } \\
\text { Transitions }\end{array}$ & $\begin{array}{c}\text { Recall } \\
\text { Probability }\end{array}$ \\
\hline-7 & 0 & 0 & \\
-6 & 0 & 0 & \\
-5 & 0 & 0 & \\
-4 & 0 & 0 & $0 / 1=.00$ \\
-3 & 0 & 0 & $1 / 2=.50$ \\
-2 & 0 & 1 & $1 / 5=.20$ \\
-1 & 1 & 2 & $2 / 5=.40$ \\
+1 & 1 & 5 & $0 / 4=.00$ \\
+2 & 2 & 5 & $0 / 4=.00$ \\
+3 & 0 & 4 & $0 / 3=.00$ \\
+4 & 0 & 4 & $0 / 2=.00$ \\
+5 & 0 & 3 & $0 / 1=.00$ \\
+6 & 0 & 2 & \\
\hline
\end{tabular}

(Manuscript received August 2, 2006; revision accepted for publication May 28, 2007.) 